\title{
Phosphorus-Doped Carbon Quantum Dots as Fluorometric Probes for Iron Detection.
}

\author{
Gopi Kalaiyarasan¹, James Joseph ${ }^{2 *}$, Pankaj Kumar ${ }^{\text {* }}$ \\ 'Department of Chemistry, Indian Institute of Science Education and Research (IISER), Tirupati, AP, India \\ 2Electrodics and Electrocatalysis Division, CSIR-Central Electrochemical Research Institute, Karaikudi, TN, India. \\ *James Joseph: jamescecri@cecri.res.in \\ *Pankaj Kumar: pankaj@iisertirupati.ac.in
}

\section{SI 1 Experimental section}

SI 1.1 Spectroscopy

The UV-vis and photoluminescence (PL) spectra of the PCQDs were measured by a Thermo Scientific Evolution 300 UV-Vis Spectrophotometer and Hitachi Fluorescence Spectrophotometer F-7ooo respectively. $3 \mathrm{~mL}$ of sample were taken in quartz cuvette for UV-vis and PL measurement. Absorbance scan was measured in the range from 190 to $1100 \mathrm{~nm}$ using $1 \mathrm{~nm}$ steps. The PL spectra were run in proper wavelength window with $1 \mathrm{~nm}$ step for different excitation wavelengths range from $240 \mathrm{~nm}$ to $440 \mathrm{~nm}$ with $10 \mathrm{~nm}$ interval. The excitation/emission bandwidth and PMT voltage were set to $5.0 \mathrm{~nm}$ and 40o V, respectively. The Fourier transform infrared (FT-IR) spectra were carried out by Bruker Optik GmbH, TENSOR 27, Germany. Before taking FT-IR spectra, the samples were dropped cast on $\mathrm{KBr}$ pellet and dried at room temperature. The XPS analysis was carried out by Thermo Scientific, MULTI LAB 2000 (Base system with X-Ray, Auger, and ISS attachments). The PCQDs was drop cast on conducting glass plate for XPS analysis. The chemical compositions were studied by XPS measurement.

\section{SI 1.2 Microscopy}

The morphology studies and crystalline analysis were carried out with a Tecnai G2 (FEI make) high-resolution transmission electron microscope (HRTEM) with EDAX accessories. Samples for HRTEM and EDAX measurements were prepared by placing drops $5 \mu \mathrm{L}$ of the solution on a carbon-coated copper grid and subsequently drying in the IR heat lamp.

\section{SI 1.3 Preparation of PCODs for $\mathrm{pH}$ and its characterization}

The $\mathrm{pH}$ was measured first for raw PCQDs, i.e., 5.2, then the $\mathrm{pH}$ was adjusted independently to 2.0 and 12.0 using $\mathrm{HCl}$ and $\mathrm{NaOH} .3 \mathrm{~mL}$ taken from these dispersions for UV-vis and PL measurements. The excitation wavelength is $310 \mathrm{~nm}$ for both dispersions to get PL spectra of PCQDs at different pHs. The maximum emission intensities at a wavelength of $440 \mathrm{~nm}$ taken to plot intensity vs. $\mathrm{pH}$ graph. The Zeta potential was measured for those samples by Particulate systems NanoPlus HD - Zeta Potential \& Nano Particle Size Analyzer. These samples were taken in a quartz flow cell for the measurement.

\section{SI 1.4 Quantum yield calculation}

The quantum yield of the synthesized PCQDs was calculated by the below equation ${ }^{1}$,

$$
\phi_{x}=\phi_{s t}\left(\frac{I_{x}}{I_{s t}}\right)\left(\frac{A_{s t}}{A_{x}}\right)\left(\frac{\eta_{x}^{2}}{\eta_{s t}^{2}}\right)
$$

Where $\Phi$ is the quantum yield, I is the fluorescence intensity, A is the absorbance at the excitation wavelength, and $\eta$ is the refractive index of the solvent. The subscript 'st' refers to standard with known quantum yield and 'x' refers to the sample. We are using excitation/emission wavelengths of $491 / 515 \mathrm{~nm}$, and QY is $95 \%$ for fluorescein in o.1 $\mathrm{M} \mathrm{NaOH}$ aqueous solution as stand$\mathrm{ard}^{2}$. Then, we are using the excitation/emission wavelengths of 310/440 $\mathrm{nm}$ to calculate relative fluorescence quantum yield of PCQDs. 


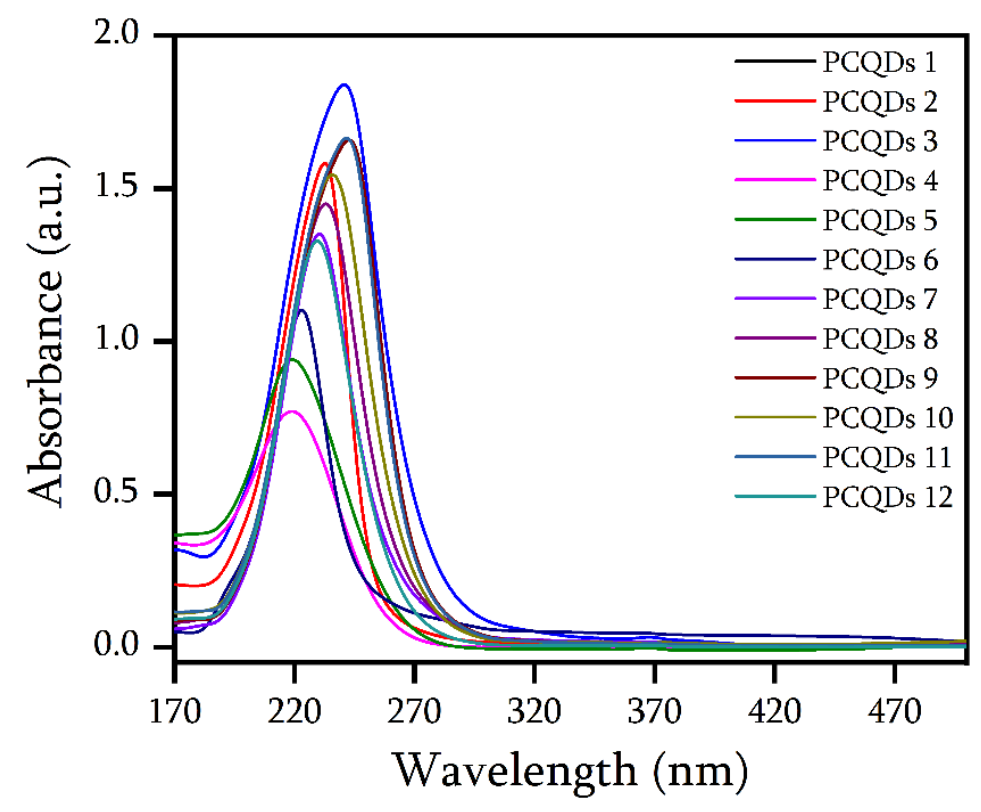

Figure S1. UV-vis absorbance spectra of various PCQDs.

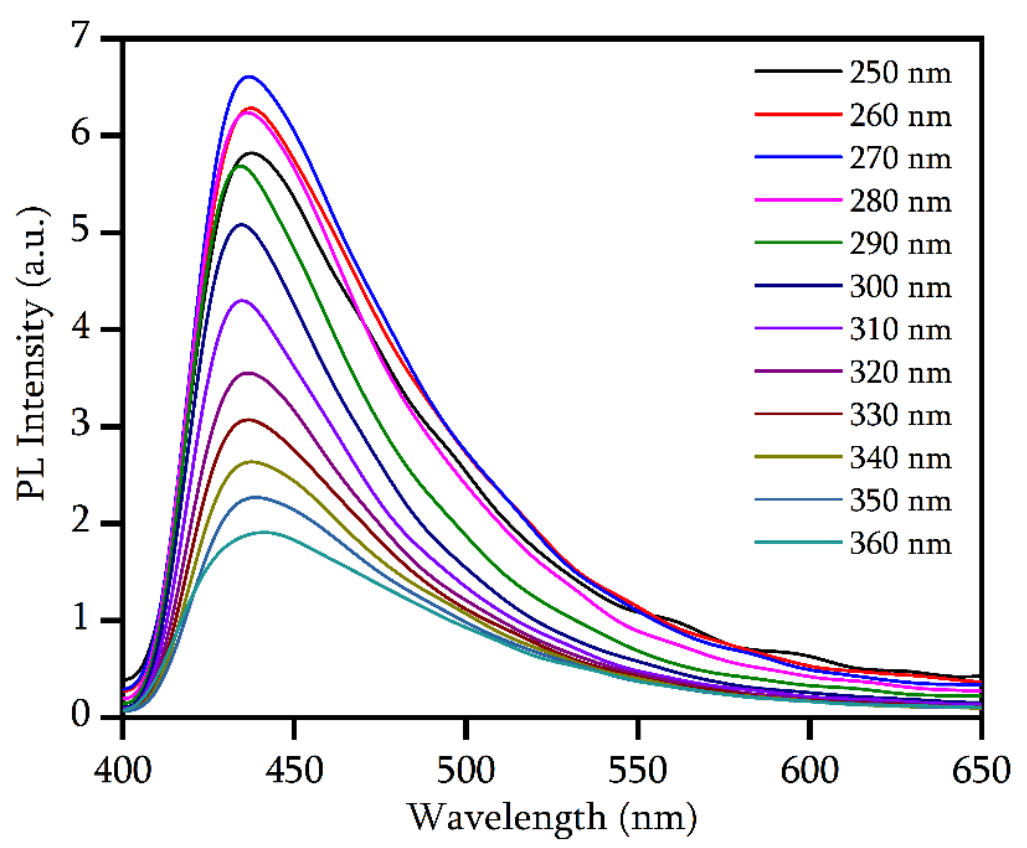

Figure S2. PL spectra of PCQDs 1 at the various excitation wavelength, synthesized from 1:1 ratio of precursor, heated at $8 \mathrm{o}^{\circ} \mathrm{C}$ for $12 \mathrm{~h}$. 


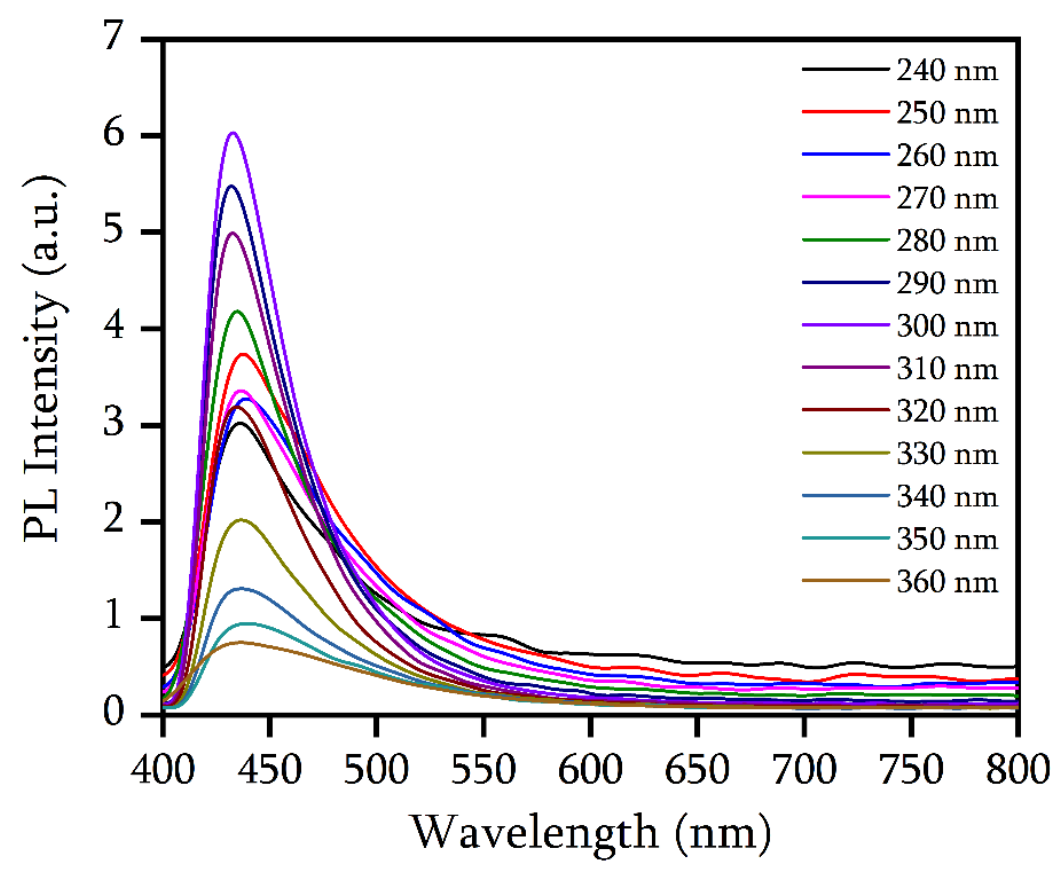

Fugure S3. PL spectra of PCQDs 2 at the various excitation wavelength, synthesized from 1:1 ratio of precursor, heated at $110{ }^{\circ} \mathrm{C}$ for $12 \mathrm{~h}$.

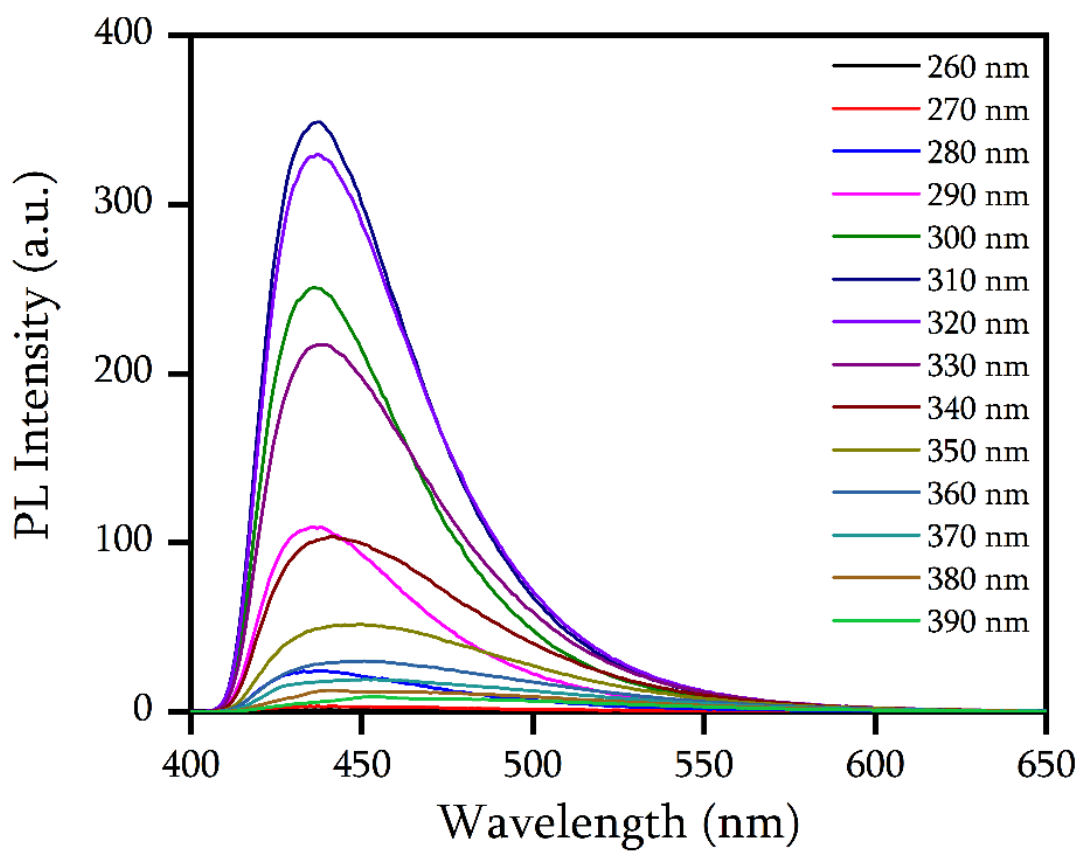

Figure $\mathrm{S}_{4}$. PL spectra of PCQDs 4 at the various excitation wavelength, synthesized from 1:1 ratio of precursor, heated at $170{ }^{\circ} \mathrm{C}$ for $12 \mathrm{~h}$. 


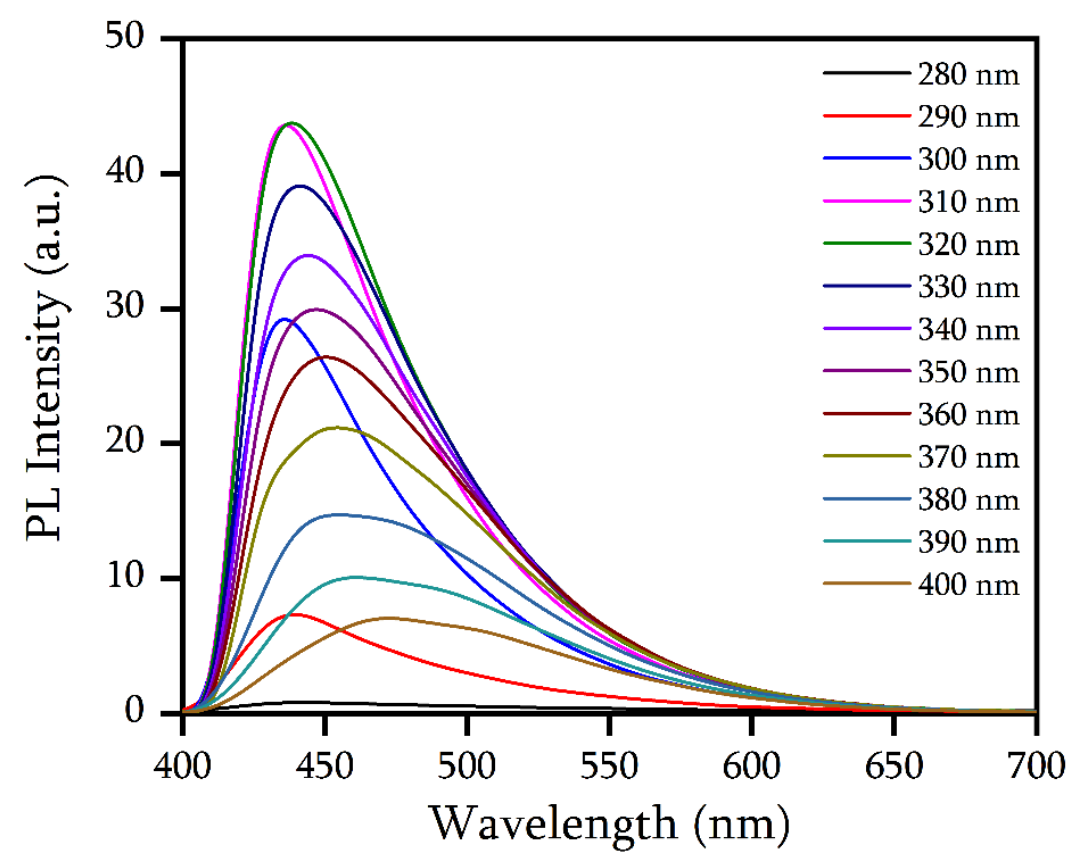

Figure $\mathrm{S}_{5}$. PL spectra of PCQDs 5 at the various excitation wavelength, synthesized from 1:1 ratio of precursor, heated at $200{ }^{\circ} \mathrm{C}$ for $12 \mathrm{~h}$.

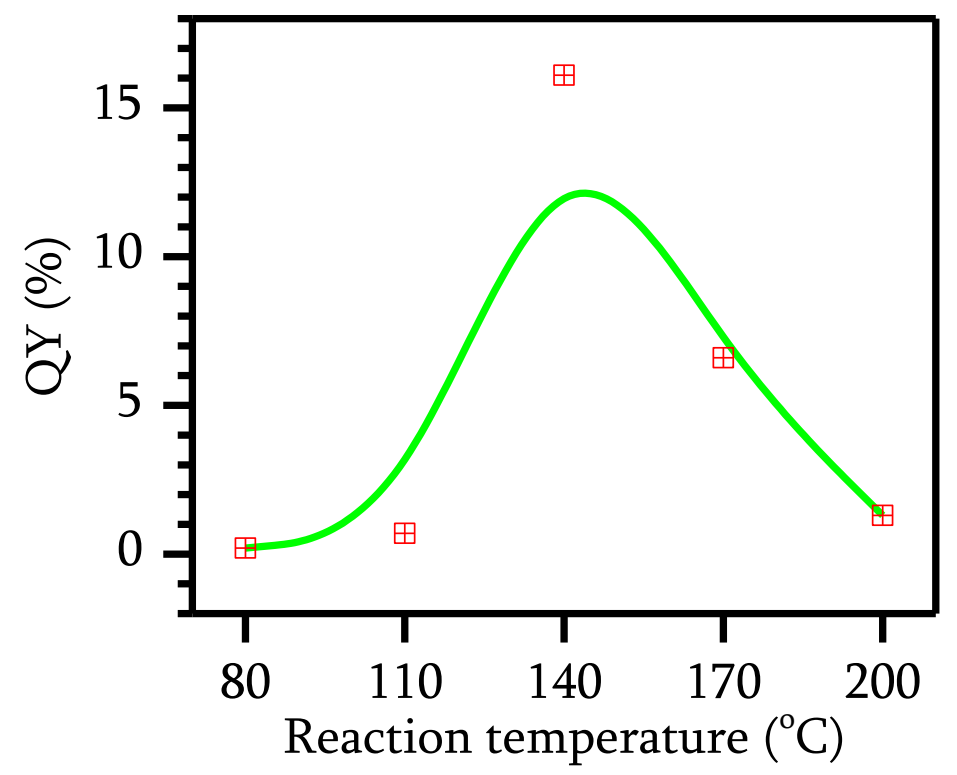

Figure S6. Quantum yield vs reaction temperature graph derived from UV-vis/PL data of listed as prepared samples. 


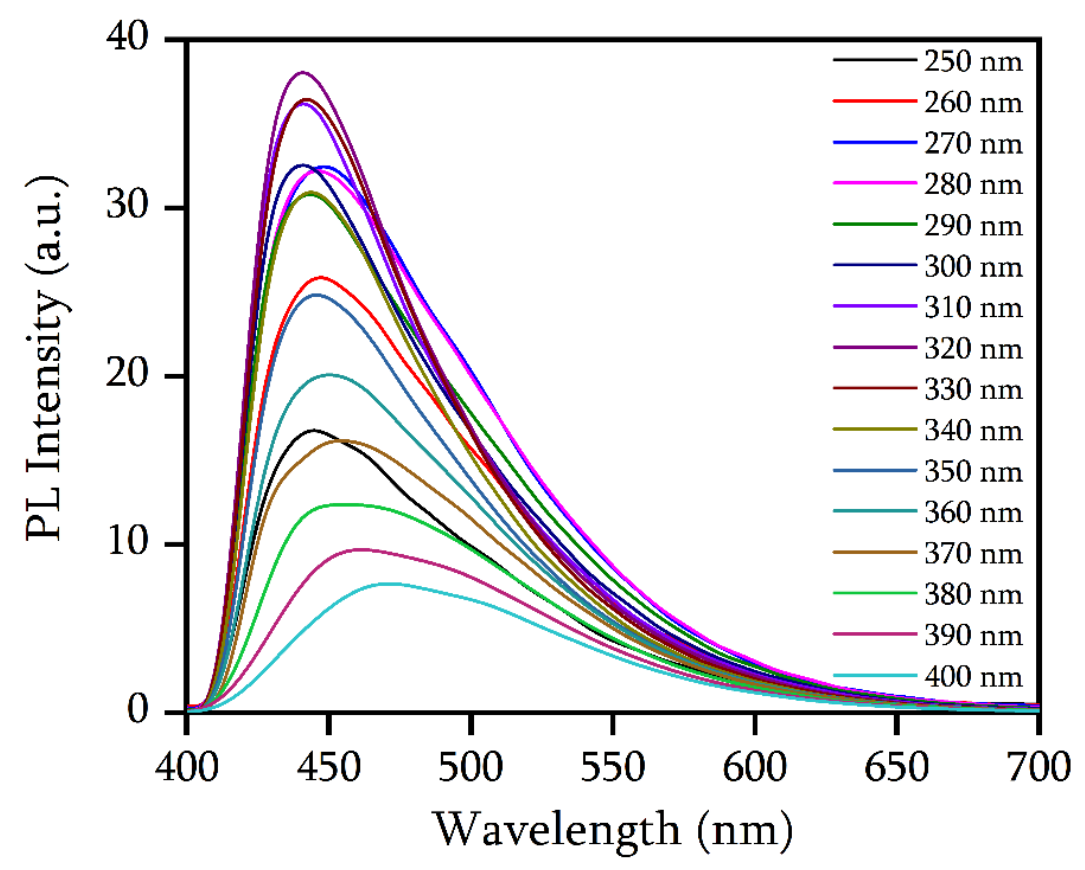

Figure S7. PL spectra of PCQDs 6 at the various excitation wavelength, synthesized from 1:1 ratio of precursor, heated at $140{ }^{\circ} \mathrm{C}$ for $6 \mathrm{~h}$.

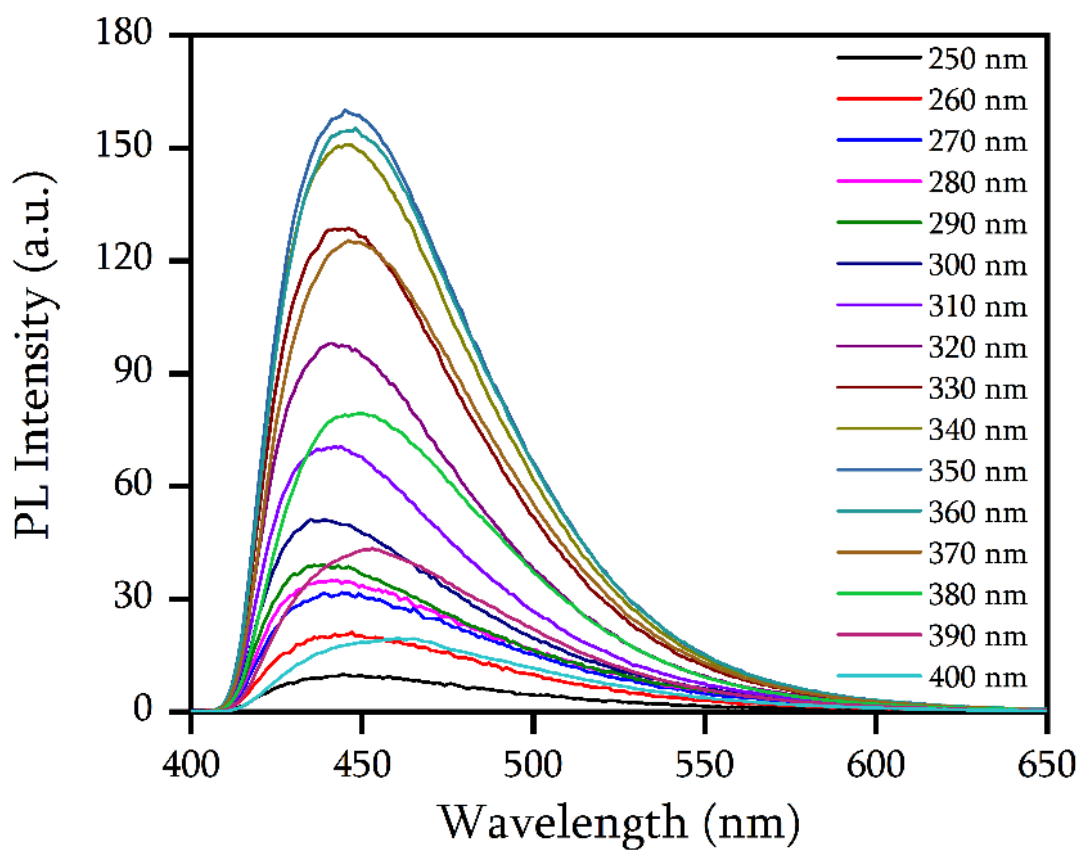

Figure S8. PL spectra of PCQDs 7 at the various excitation wavelength, synthesized from 1:1 ratio of precursor, heated at $140{ }^{\circ} \mathrm{C}$ for $18 \mathrm{~h}$. 


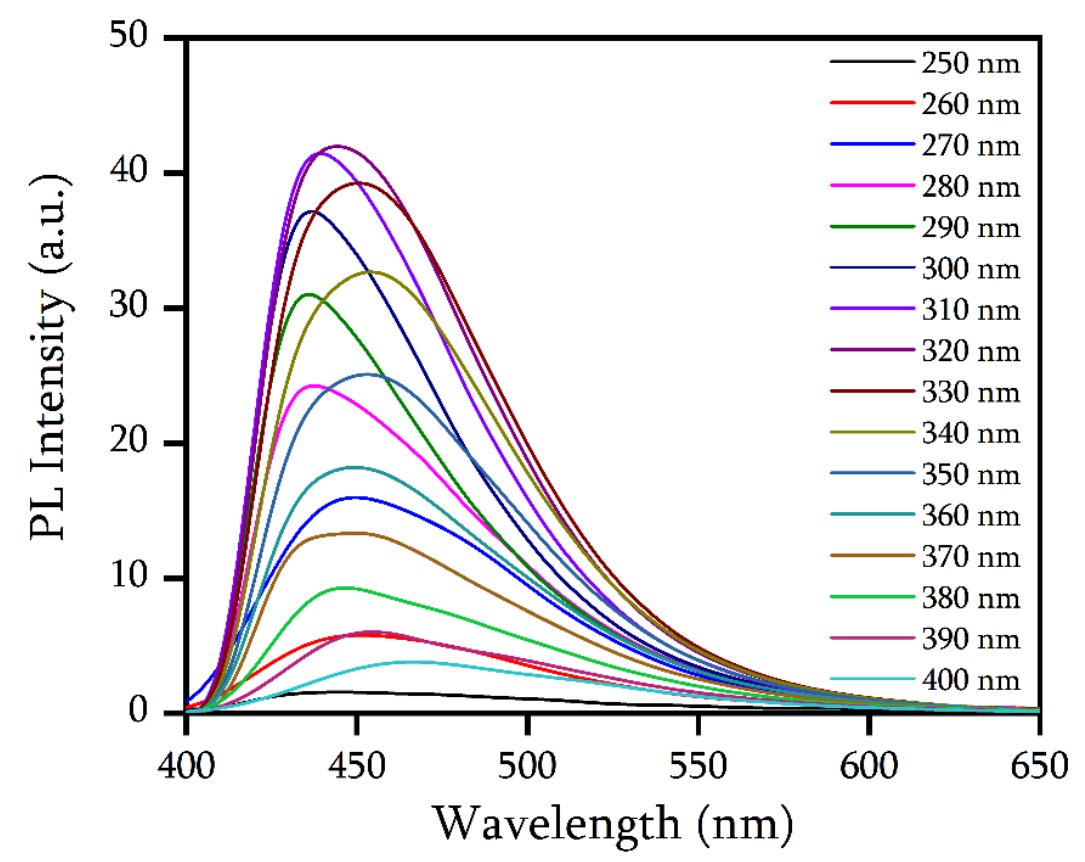

Figure S9. PL spectra of PCQDs 8 at the various excitation wavelength, synthesized from 1:1 ratio of precursor, heated at $140{ }^{\circ} \mathrm{C}$ for $24 \mathrm{~h}$.

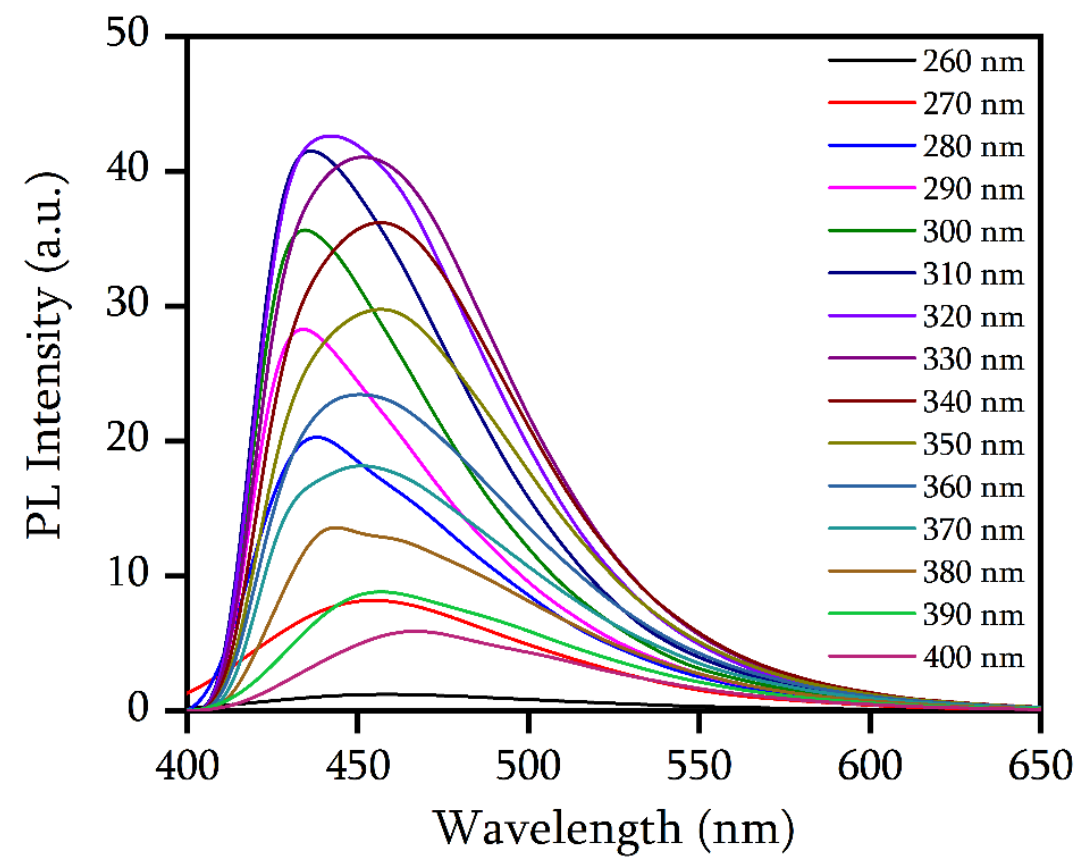

Figure S1o. PL spectra of PCQDs 9 at the various excitation wavelength, synthesized from 1:2 ratio of precursor, heated at $140{ }^{\circ} \mathrm{C}$ for $12 \mathrm{~h}$. 


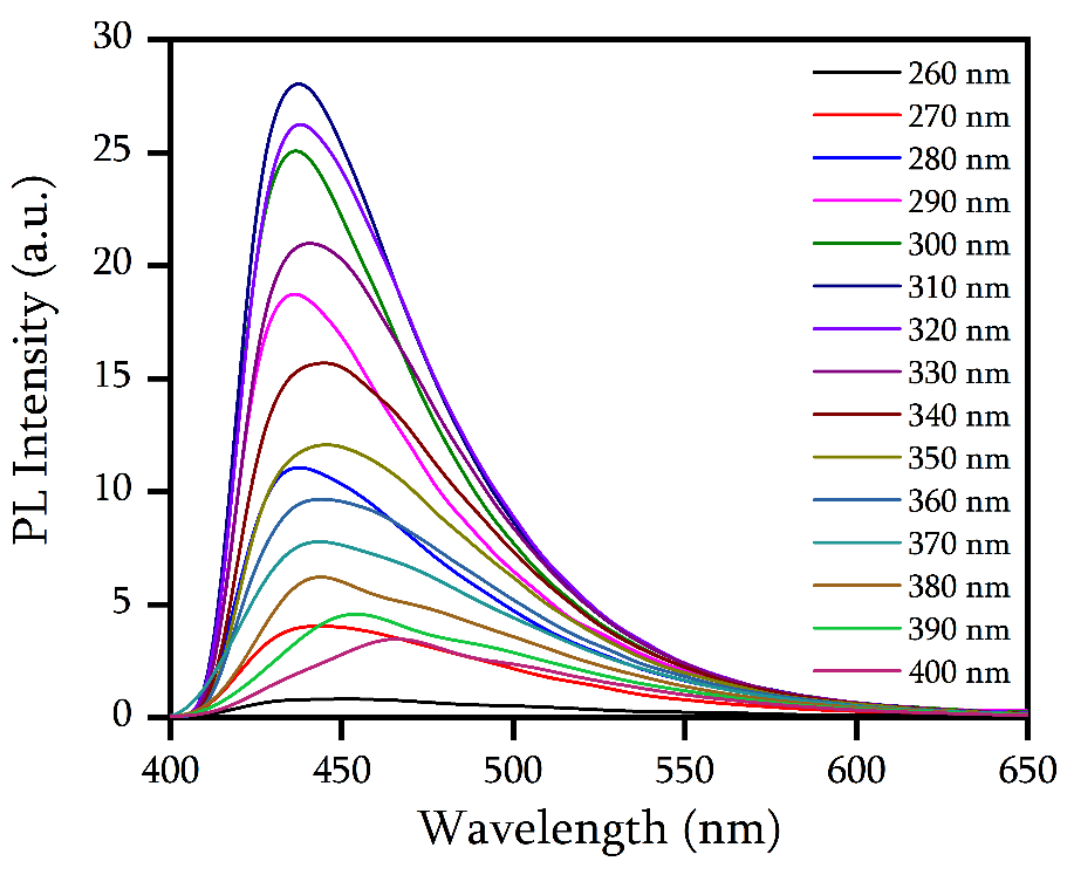

Figure S11. PL spectra of PCQDs 10 at the various excitation wavelength, synthesized from 2:1 ratio of precursor, heated at $140{ }^{\circ} \mathrm{C}$ for $12 \mathrm{~h}$.

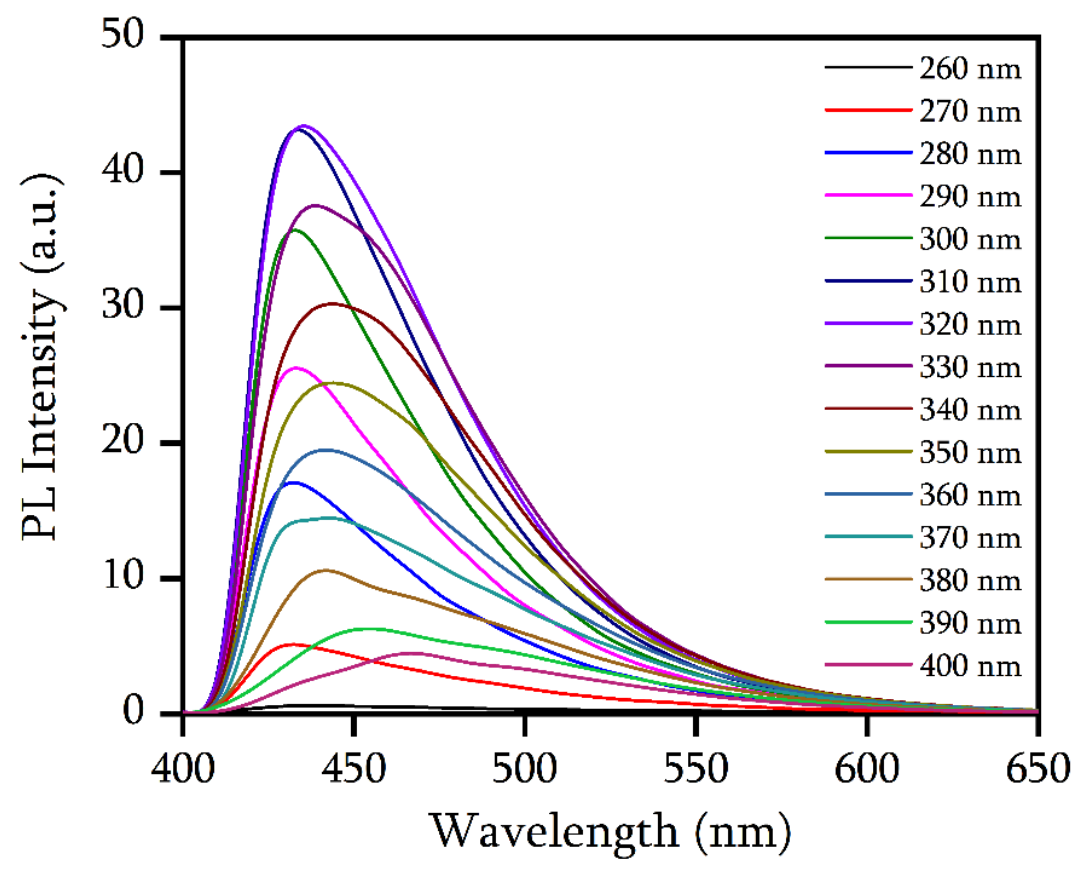

Figure S12. PL spectra of PCQDs 12 at the various excitation wavelength, synthesized from 3:1 ratio of precursor, heated at $140^{\circ} \mathrm{C}$ for $12 \mathrm{~h}$. 


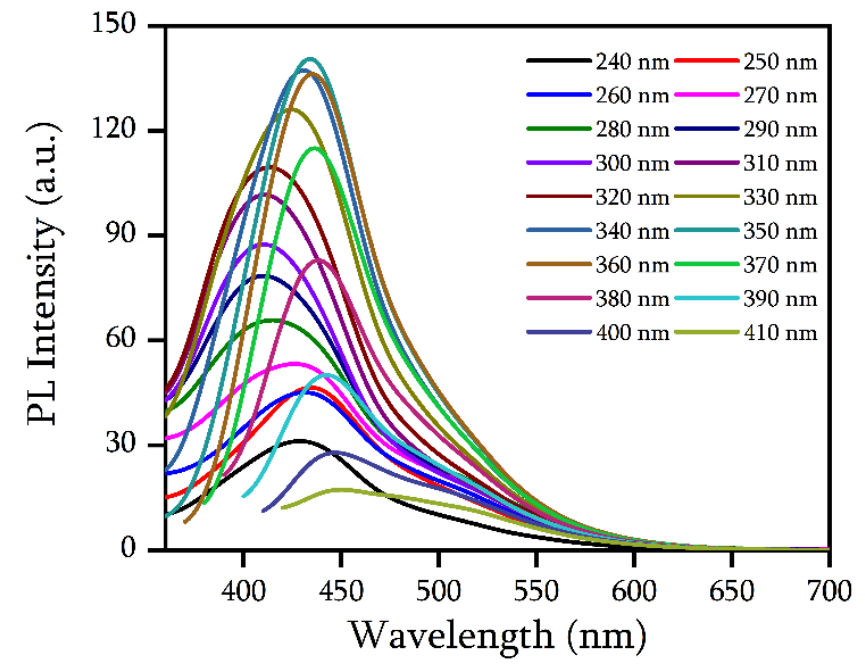

Figure S13. PL spectra of undoped CQDs.

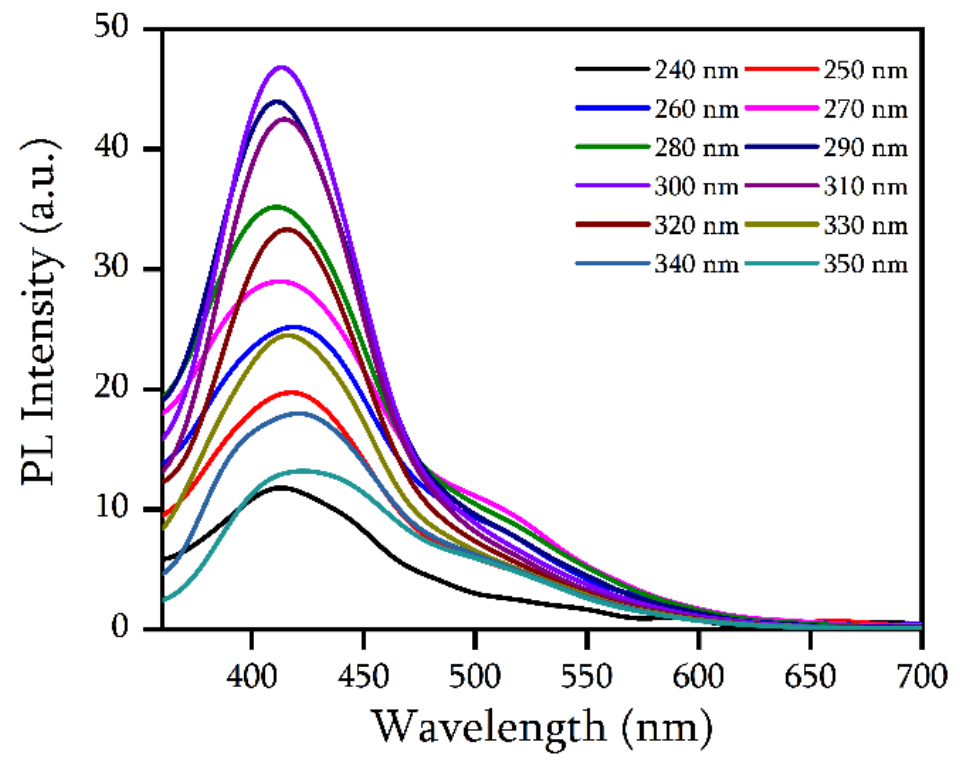

Figure S14. PL spectra of PCQDs $s_{\mathrm{sp}}$ 


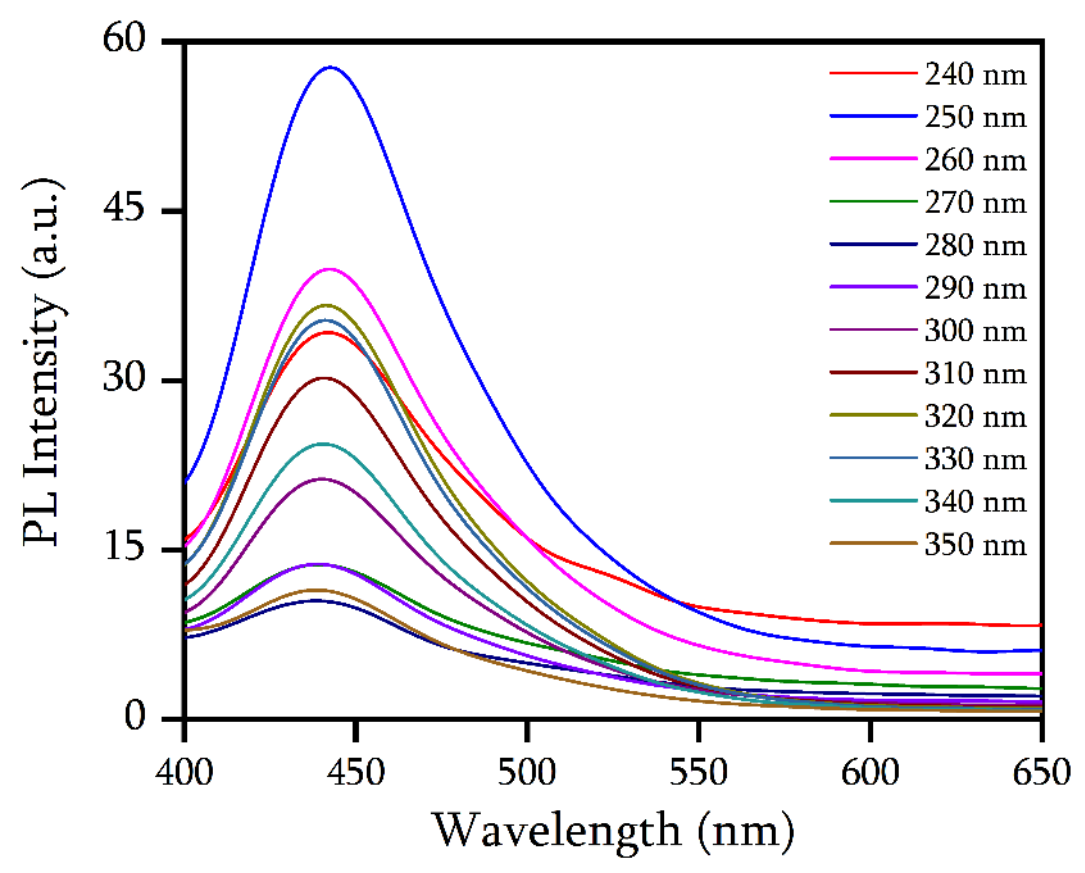

Figure S15. PL spectra of PCQDs at $\mathrm{pH}$ 2.0 with various excitation wavelengths.

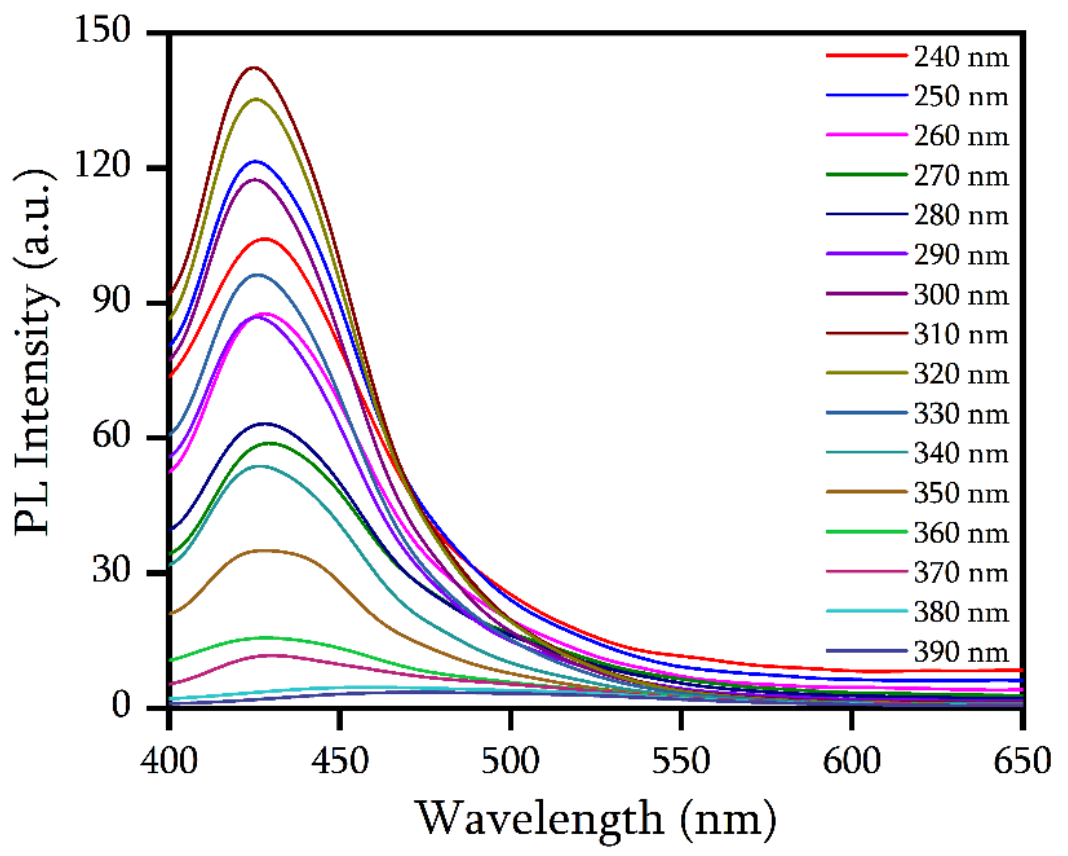

Figure S16. PL spectra of PCQDs at $\mathrm{pH}$ 12.0 with various excitation wavelengths. 


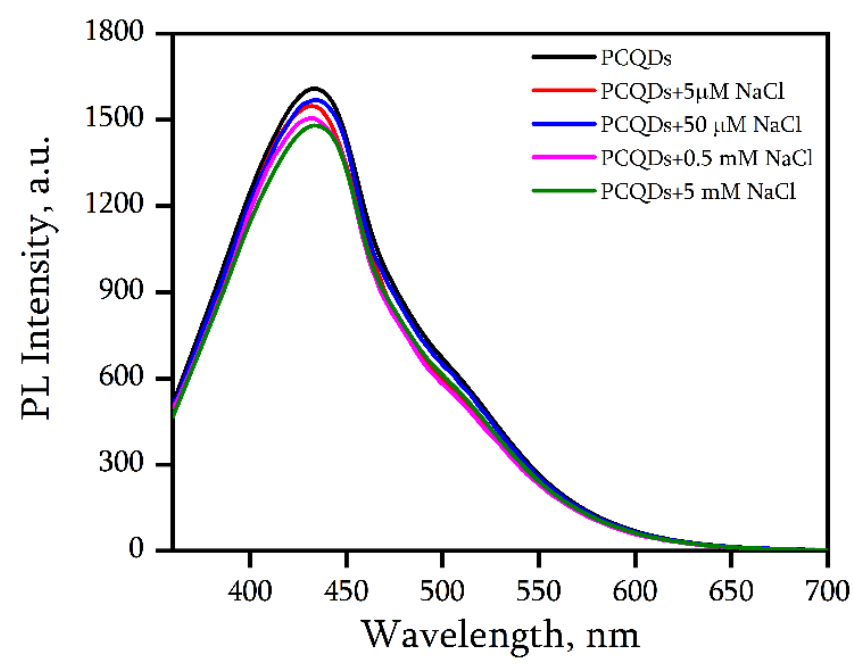

Figure S17. PL spectra of PCQDs in presence of $\mathrm{NaCl}$ with various concentration.

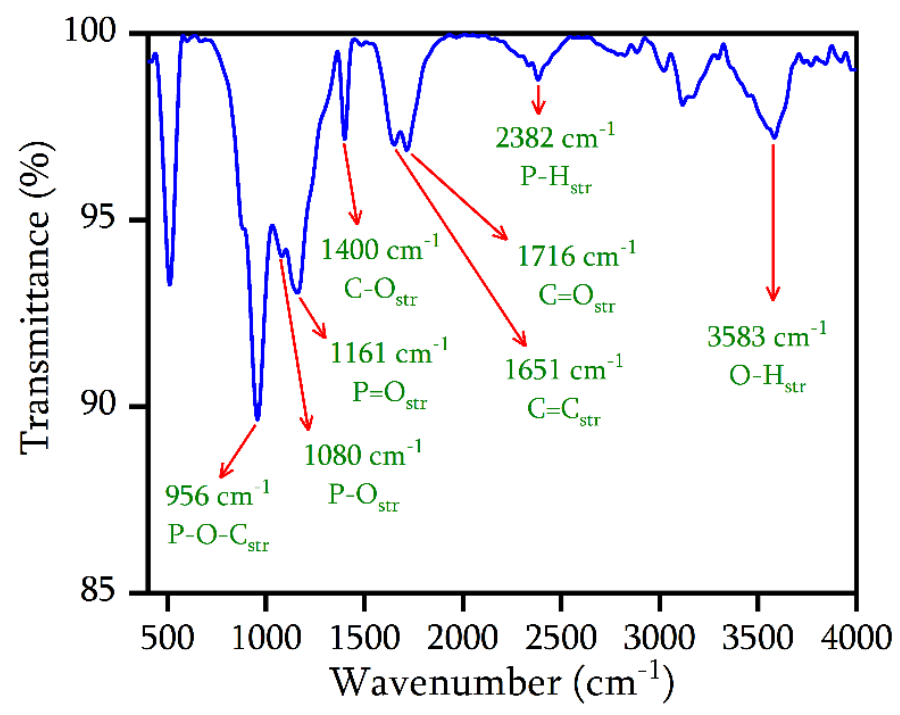

Figure S18. FTIR spectrum of PCQDs 3. 

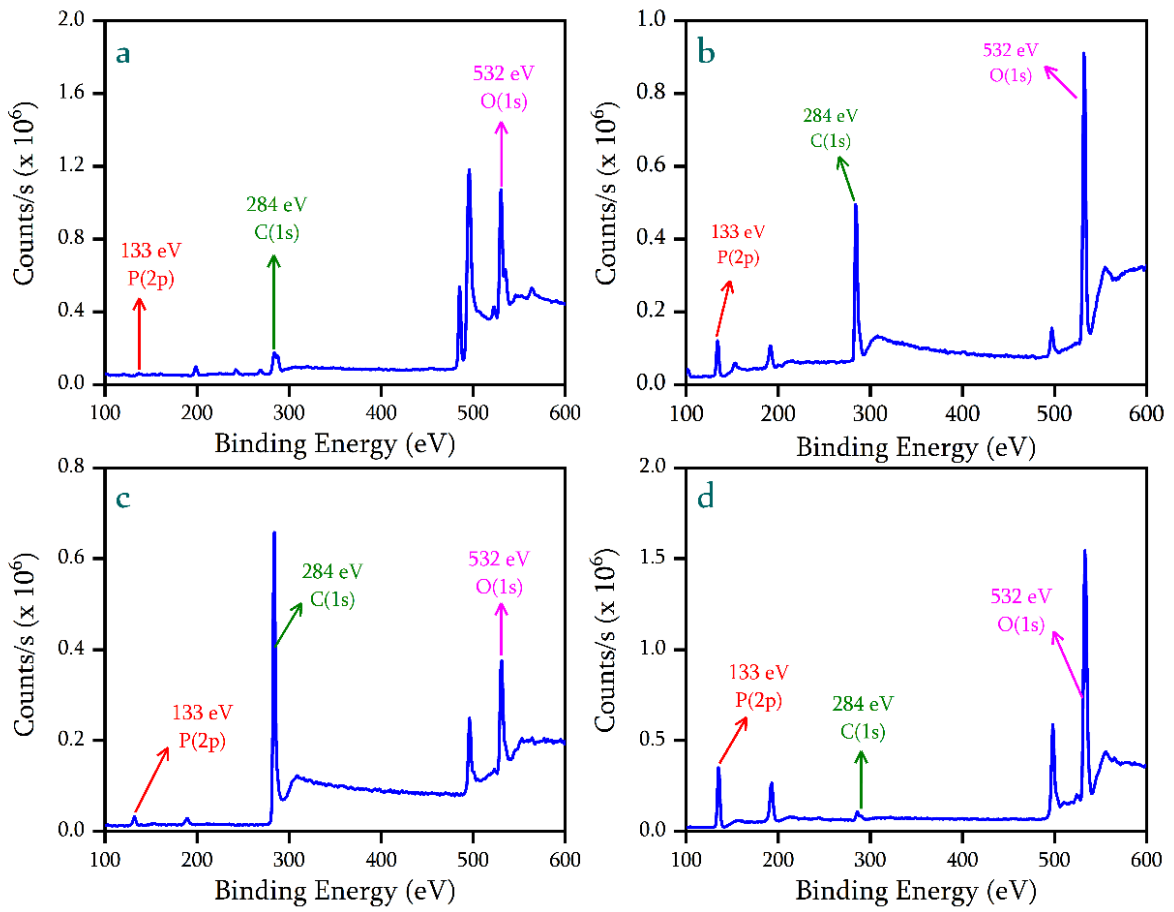

Figure S19. XPS survey spectra of (a) PCQDs 1, (b) PCQDs 3, (c) PCQDs 11, (d) PCQDs sp.

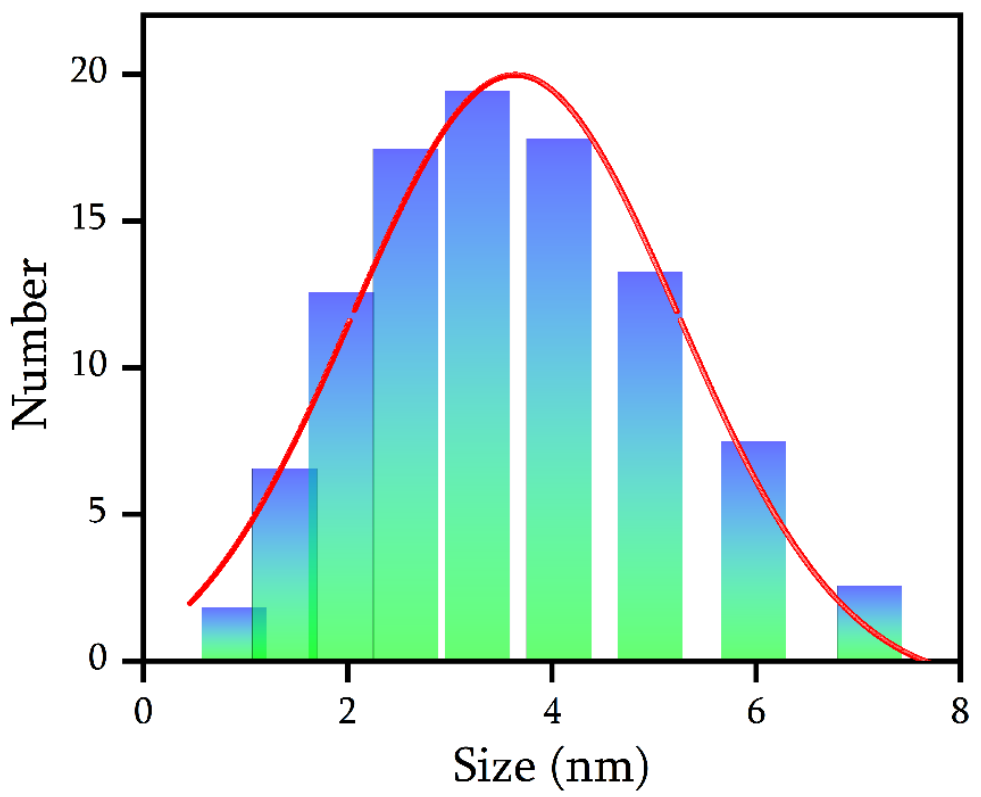

Figure S2o. DLS number distribution curve. 


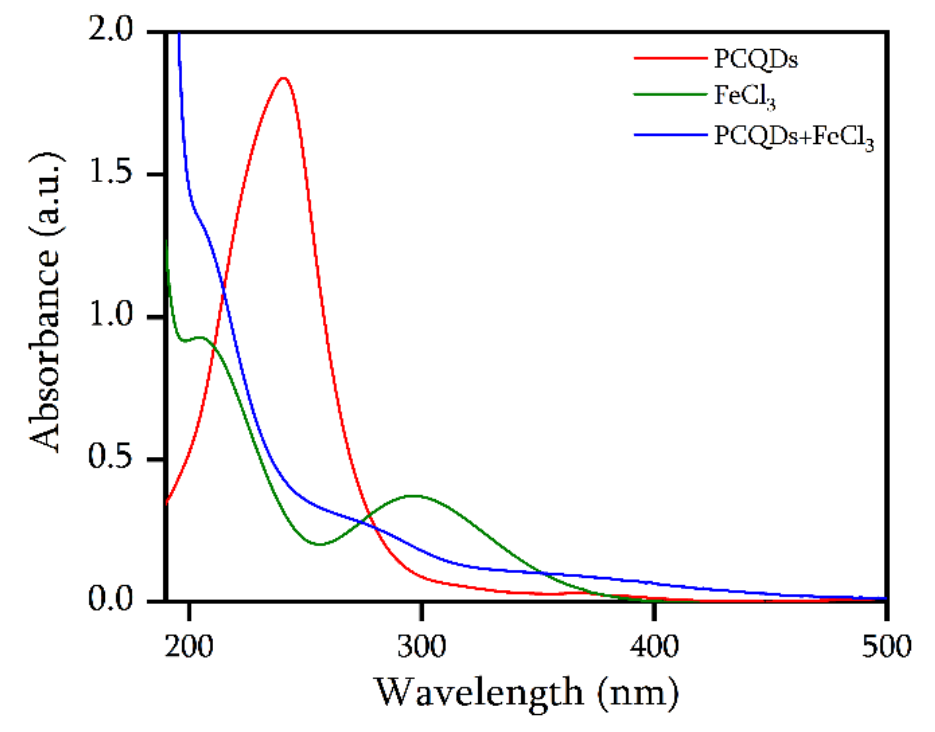

Figure S21. UV-vis absorbance spectra of aqueous solution of PCQDs, $5 \mu \mathrm{M}$ of $\mathrm{FeCl}_{3}$, and mixture of both.

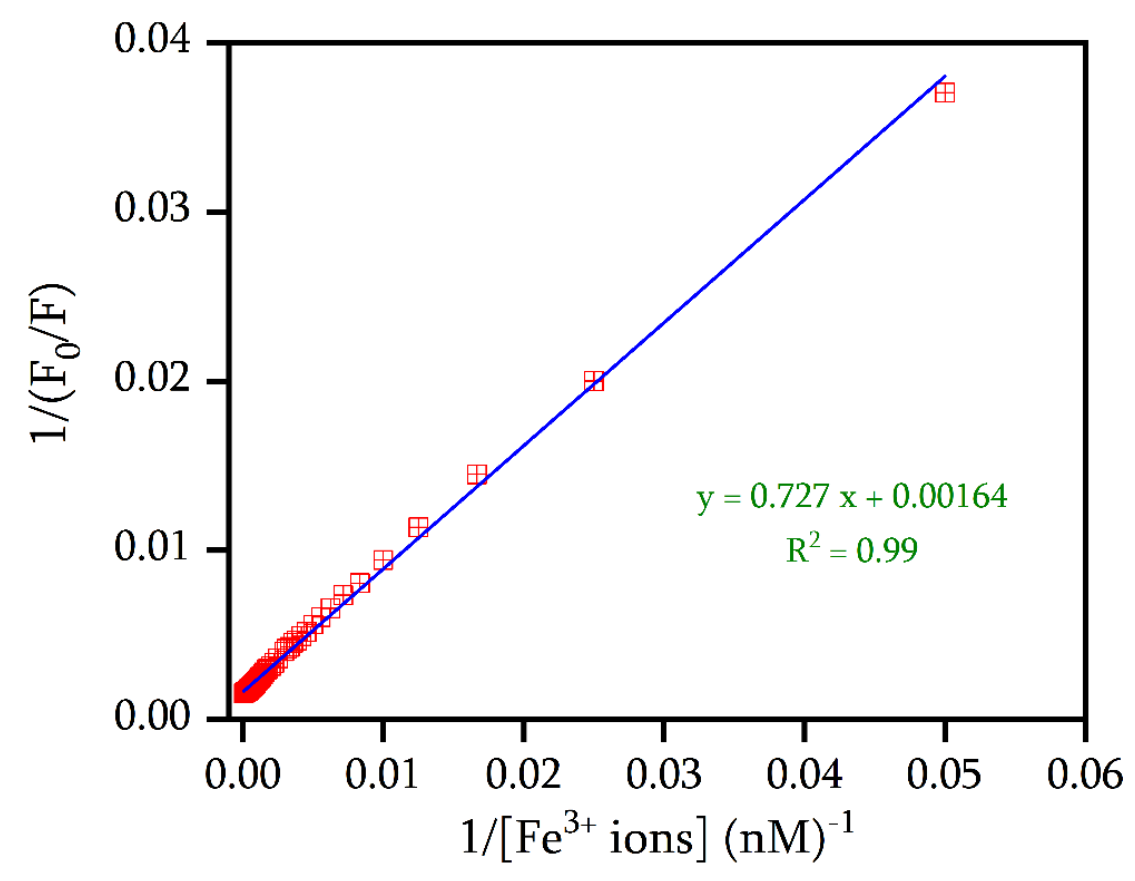

Figure S22. Lineweaver- Burk plot for the measurement of binding constant, derived from PL quenching results. 


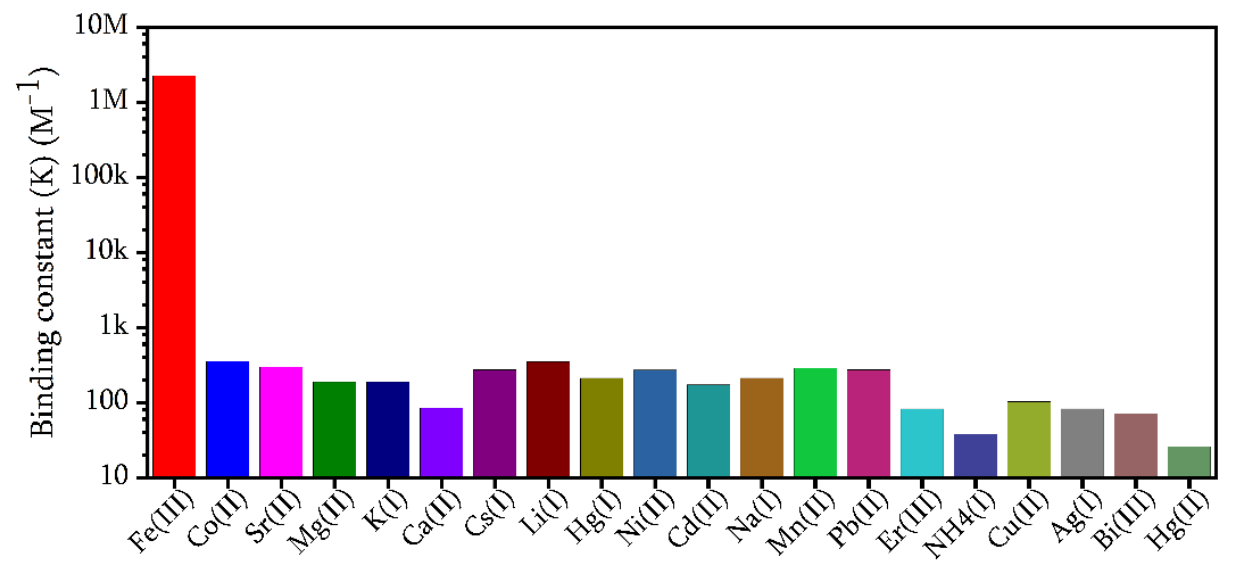

Figure S23. Binding constant values of metal ions for phosphorus doped CQDs.

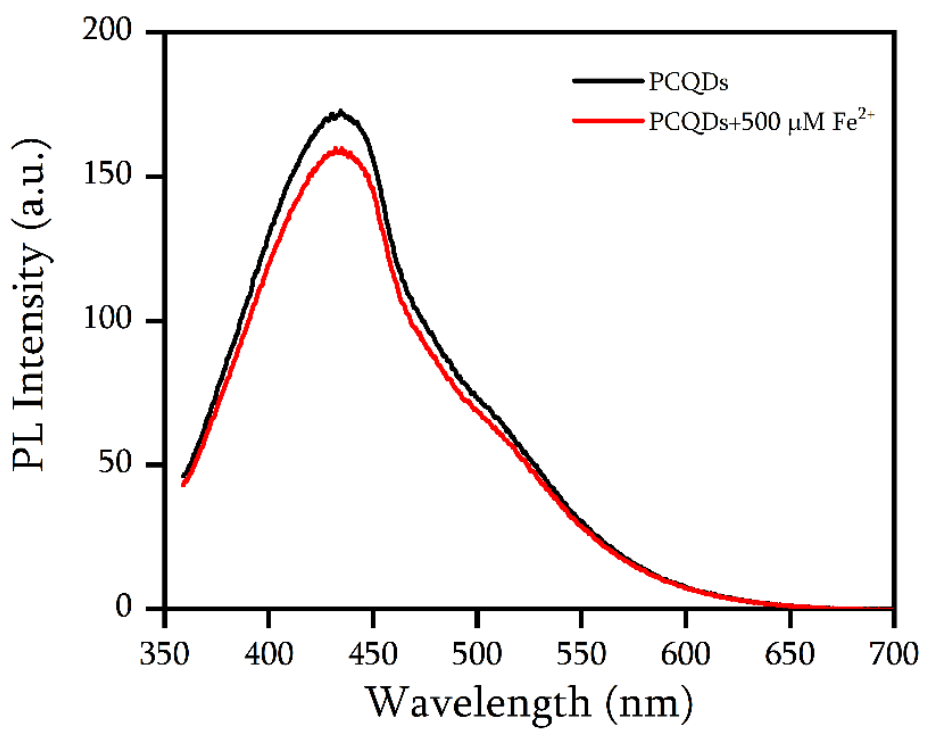

Figure S24. PL spectra of PCQDs before and after addition of $0.5 \mathrm{mM}$ of $\mathrm{Fe}^{2+}$ at excitation wavelength of $310 \mathrm{~nm}$. 


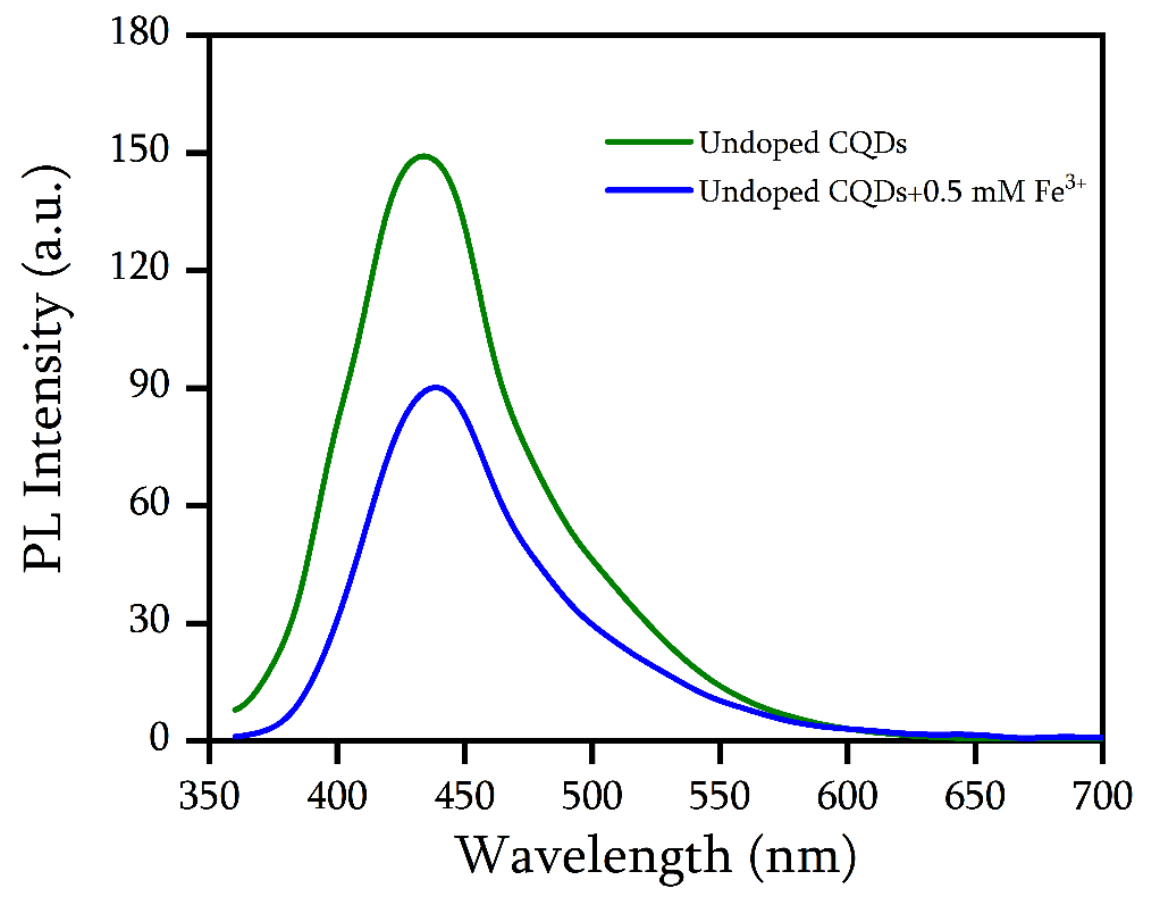

Figure S25. PL spectra of undoped CQDs before and after addition of $0.5 \mathrm{mM}$ of $\mathrm{Fe}^{3^{+}}$ions at excitation wavelength of $350 \mathrm{~nm}$.

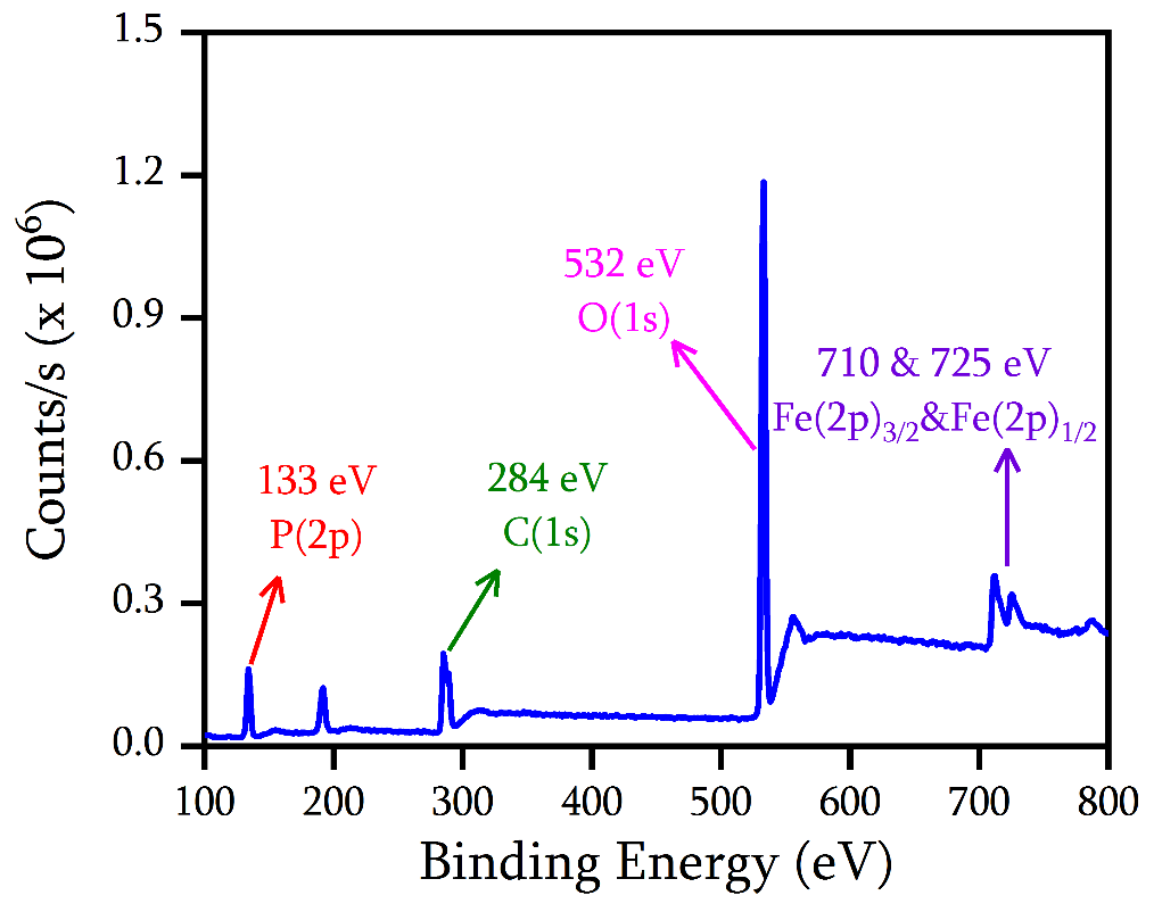

Figure S26. XPS survey spectram of PCQDs-Fe complex. 


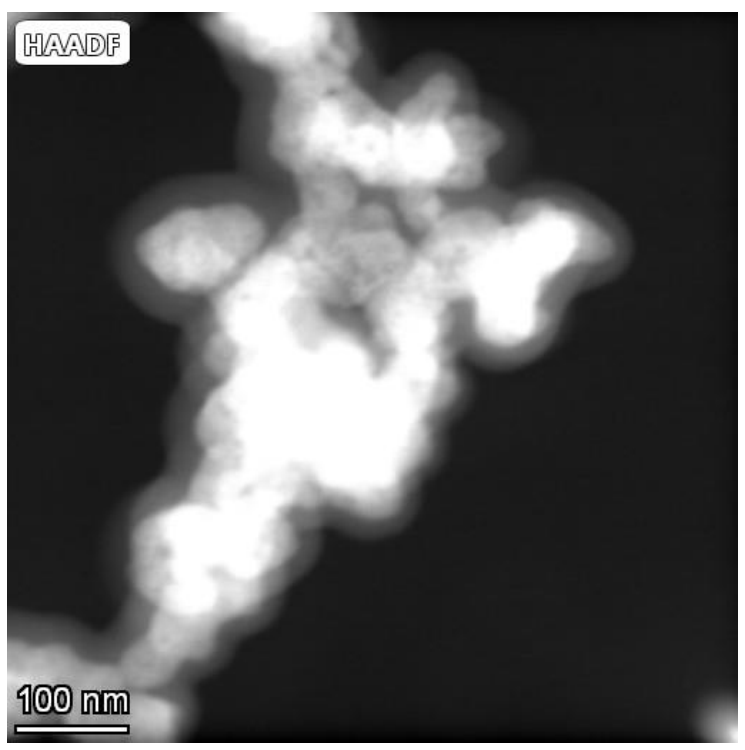

Figure S27. HAADF EDS image of PCQDs-Fe complex.
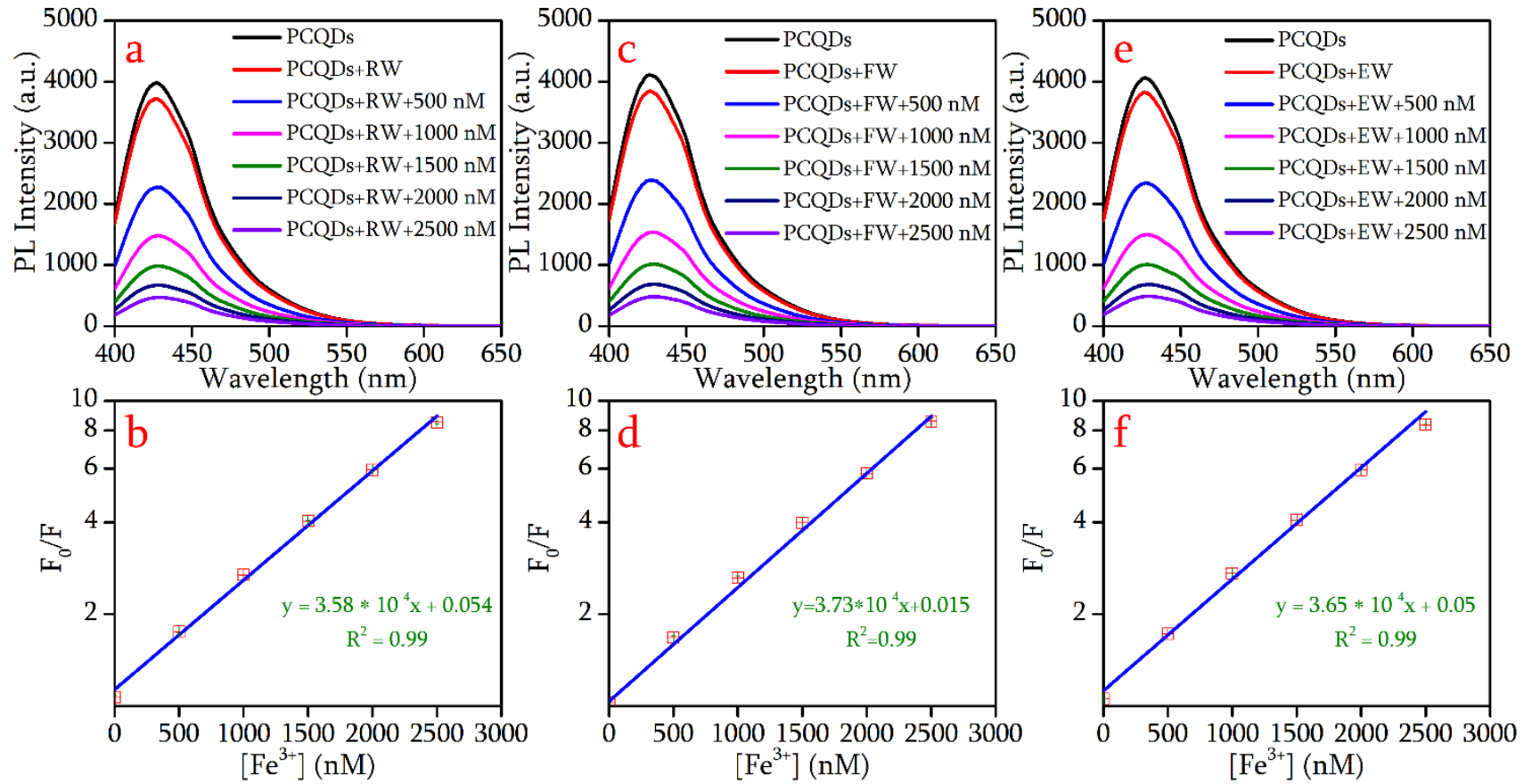

Figure S28. PL spectra and its standard addition plots of PCQDs with (a \& b) raw water (RW), (c \& d) filtered water (FW), and (e \& f) ejected water $(\mathrm{EW})$ samples with standard addition of $\mathrm{Fe}^{3+}$. 
Table S1. The amount of P, C, O in different PCQDs.

\begin{tabular}{|c|c|c|c|c|c|c|c|c|c|c|c|c|}
\hline \multirow{2}{*}{ Sample } & \multicolumn{3}{|c|}{$\mathrm{P}(2 \mathrm{p}), \%$} & \multicolumn{4}{|l|}{$C(1 \mathrm{~s}), \%$} & \multicolumn{4}{|c|}{$\mathrm{O}(\mathrm{ss}), \%$} & \multirow{2}{*}{$\mathrm{P}: \mathrm{O}$} \\
\hline & P-C & $\mathrm{P}-\mathrm{O}$ & Total & $\mathrm{C}-\mathrm{C} / \mathrm{C}=\mathrm{C}$ & C-O/C-P & $\mathrm{C}=\mathrm{O}$ & Total & $\mathrm{O}=\mathrm{C}$ & $\mathrm{O}=\mathrm{P}$ & $\mathrm{OH}_{2}$ & Total & \\
\hline PCQDs 1 & 0.3 & 0.6 & 0.9 & 1.9 & 1.6 & 0.8 & $4 \cdot 3$ & 27.4 & 43.1 & 24.0 & 94.5 & 0.01 \\
\hline PCQDs 3 & $5 \cdot 7$ & 3.2 & 8.9 & 18.9 & $7 \cdot 4$ & 2.4 & 28.7 & 16.8 & 44.6 & 1.1 & 62.5 & 0.14 \\
\hline PCQDs 11 & 0.3 & 0.5 & 0.8 & 6.1 & 4.8 & 6.5 & $17 \cdot 4$ & 30.2 & 30.7 & 20.7 & 81.6 & 0.01 \\
\hline $\mathrm{PCQDs}_{\mathrm{sp}}$ & 5.1 & 3.7 & 8.8 & $7 \cdot 7$ & 2.3 & 4.9 & 14.9 & 30.9 & 41.2 & 4.1 & 76.2 & 0.11 \\
\hline
\end{tabular}

\section{Quantum yield model calculation}
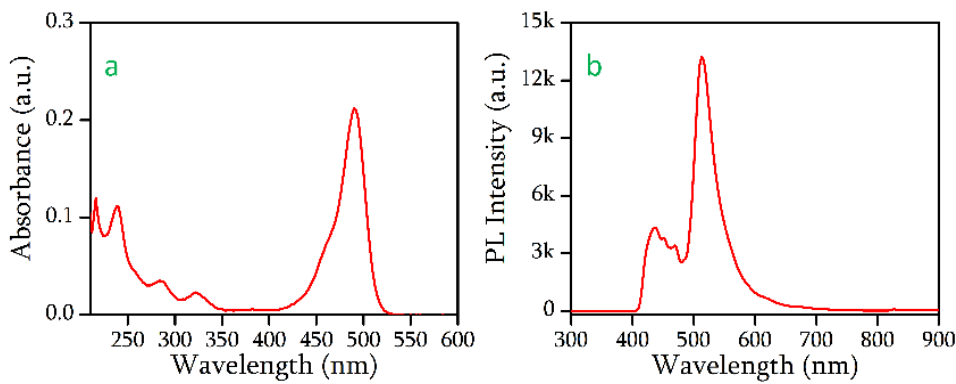

Figure S29. UV-vis and PL spectra of o.1 M NaOH solution of fluorescein as a standard for quantum yield calculation.

The o.1 M NaOH solution of fluorescein was used as standard for quantum yield calculation. The UV-vis and Fluorescence spectra are shown in Figure S28. From this spectra, we take the value of absorbance at $491 \mathrm{~nm}$ and fluorescence at $515 \mathrm{~nm}$. We have demonstrated a model calculation using the PCQDs 3 data.

$$
\phi_{x}=\phi_{s t}\left(\frac{I_{x}}{I_{s t}}\right)\left(\frac{A_{s t}}{A_{x}}\right)\left(\frac{\eta_{x}^{2}}{\eta_{s t}^{2}}\right)
$$

$I_{x}=671($ from Figure $1 b)$

$I_{s t}=13140($ from Figure S26)

$A_{s t}=0.2134($ from Figure S26)

$A_{x}=0.064\left(\right.$ from Figure $\left.S_{1}\right)$

$\eta_{\mathrm{x}} \& \eta_{\text {st }}$ are same.

Therefore,

$$
\begin{gathered}
\phi_{x}=95\left(\frac{671}{13140}\right)\left(\frac{0.2134}{0.064}\right) \% \\
\phi_{x}=95 \times 0.0510 \times 3.3343 \% \\
\phi_{x}=16.1 \%
\end{gathered}
$$

In similar way, we have calculated the quantum yield for remaining all PCQDs. 


\section{Binding constant model calculation}

Binding constant can be calculated by Lineweaver-Burk equation.

$\frac{1}{F_{0}-F}=\frac{1}{F_{0}}+\frac{1}{K F_{0}} \frac{1}{[Q]}$

Where $F_{o}$ and $F$ are fluorescence intensity of PCQDs before and after the addition of analytes. K and [Q] are binding constant and the concentration of analytes, respectively.

For $\mathrm{Co}^{2+}, \mathrm{F}=8045, \mathrm{~F}_{\mathrm{o}}=9465, \mathrm{Q}=0.5 \mathrm{mM}$,

$$
\begin{gathered}
\frac{1}{9465-8045}=\frac{1}{9465}+\frac{1}{K \times 9465} \frac{1}{0.0005} \\
7.042 \times 10^{-4}=1.056 \times 10^{-4}+\frac{1.056 \times 10^{-4}}{K} \times 2000 \\
7.042 \times 10^{-4}-1.056 \times 10^{-4}=0.2112 \times \frac{1}{K} \\
\frac{5.986 \times 10^{-4}}{0.2112}=\frac{1}{K} \\
28.34 \times 10^{-4}=\frac{1}{K} \\
\mathrm{~K}=\frac{1}{28.34 \times 10^{-4}} \\
\mathrm{~K}=352.85
\end{gathered}
$$

Therefore, binding constant (K) for $\mathrm{Co}^{2+}$ is $352.85 \mathrm{M}^{-1}$

\section{Bimolecular quenching rate constant $\mathrm{k}_{\mathrm{q}}$ calculation}

$$
\frac{F_{0}}{F}=1+K_{S V}[Q]=1+k_{q} \tau_{0}[Q]
$$

We know,

Ksv from Figure 5b, i.e. $1.48 \times 10^{6} \mathrm{M}^{-1}$

Lifetime from Figure 2c, i.e. 10.4 ns

$$
\begin{gathered}
K_{S V}=k_{q} \tau_{0} \\
1.48 \times 10^{6} \mathrm{M}=\mathrm{k}_{\mathrm{q}} \times 10.4 \times 10^{-9} \mathrm{~s} \\
0.1423 \times 10^{6} \times 10^{9}=\mathrm{k}_{\mathrm{q}}
\end{gathered}
$$

Therefore, $\mathrm{k}_{\mathrm{q}}=1.423 \times 10^{14} \mathrm{M}^{-1} \mathrm{~s}^{-1}$

\section{References}

(1) Kalaiyarasan, G.; Joseph, J. Determination of Vitamin B12 via pH-Dependent Quenching of the Fluorescence of Nitrogen Doped Carbon Quantum Dots. Microchim. Acta 2017, 184 (10), 3883-3891.

(2) Brouwer, A. M. Standards for Photoluminescence Quantum Yield Measurements in Solution (IUPAC Technical Report). Pure Appl. Chem. 2011, 83 (12), 2213-2228. 